\title{
Entropy generation analysis of engineered heat transfer fluids under a constant surface temperature
}

\author{
G. Soriano ${ }^{1}$, G. Bravo ${ }^{1,2}$, P. Guevara ${ }^{1,2}$ \& F. Porras ${ }^{1,2}$ \\ ${ }^{1}$ Centro de Energías Renovables y Alternativas CERA-Escuela Superior \\ Politécnica del Litoral ESPOL, Ecuador \\ ${ }^{2}$ Instituto Nacional de Eficiencia Energética y Energías Renovables, \\ Ecuador
}

\begin{abstract}
An assessment of the use of engineered heat transfer fluids working under constant wall temperature conditions in the turbulent regime is presented. An analysis of entropy generation and pumping power on the system working with different engineered heat transfer fluids is performed. Three types of fluids are considered: multiwalled carbon nanotube (MWCNT) based nanofluids, slurries with microencapsulated phase change materials (MPCM) and a mixture of both fluids. Specific heat, thermal conductivity and viscosity of the fluids are included in the analysis using theoretical and experimental results available in literature. Nanofluids in the system result on greater entropy generation and pumping power consumption when compared with base fluid. MPCMs slurries produce the minimum entropy generation and pumping power consumption. Mixtures are affected by the content of nanofluids resulting in a performance below of MPCMs slurries. The improvement on the heat capacity of the fluid produced by the Microencapsulated phase change material is the main factor in reducing entropy generation and pumping power consumption for the system. Under the conditions assessed, the increase in viscosity offsets the increase in thermal conductivity on the MWCNT based nanofluids. On the other hand in the case of MPCM slurries, the increase in heat capacity outweighs the reduction in thermal conductivity and increase in viscosity.
\end{abstract}

Keywords: entropy, engineered fluids, MWCNT nanofluids, MPCM slurries. 


\section{Introduction}

Several initiatives for the development of novel heat transfer fluids with improved thermophysical properties have been conducted in the last decades. The development of these new fluids have the potential of increasing energy efficiency and reduce capital cost with smaller systems [1, 2]. The most promising applications of these fluids are in closed loop heat transfer systems found on processing and power industries, district cooling, HVAC, refrigeration and microelectronics cooling.

The desirable properties of a heat transfer fluid used in closed systems are: high thermal conductivity, high heat capacity, low viscosity, stability, durability, non-toxic and chemically inert [3, 4]. Two options have been explored to develop better engineered fluids: nanofluids and slurries of microencapsulated phase change materials. Nanofluids which exhibit a trade-off between thermal conductivity and viscosity $[3,5]$, and slurries of microencapsulated phase change material which present an increased heat capacity along with an increment in viscosity [6]. Additionally, efforts to combine nanofluids and MPCMs slurries have been done by Alvarado et al. [7] and Tumuluri et al. [8].

The tradeoffs between properties make the selection of the appropriate fluid for a given application a complex task. A candidate methodology for selecting the appropriate fluid and system design is entropy generation minimization. Singh et al. [9] used entropy generation minimization methodology to study alumina based nanofluids and Bejan $[10,11]$ developed the methodology for analyzing entropy generation in forced convective heat transfer with various geometries. Şahin [12] developed an entropy generation model for internal flow at constant surface temperature and turbulent conditions.

The present work compares mixtures containing Microencapsulated Phase Change Material (MPCM) and multiwalled carbon nanotube based nanofluid using entropy generation analysis and pump power consumption.

\section{Methods}

$\operatorname{Density}(\rho)$, specific heat $\left(\mathrm{C}_{\mathrm{p}}\right)$, thermal conductivity $(\mathrm{K})$, and dynamic viscosity $(\mu)$ are the main thermophysical properties responsible for heat transfer behavior. In this work, an internal flow under constant wall temperature $\overline{T_{w}}=28^{\circ} \mathrm{C}$ with eicosene $\left(\mathrm{C}_{20} \mathrm{H}_{40}\right)$ as the phase change material and multiwalled carbon nanotube based nanofluids are chosen.

\subsection{Blend properties model}

Density is modeled using simple mixing theory to define density equation (1) [13].

$$
\rho_{e f f}=\rho_{n f} \varphi_{n f}+\rho_{\text {Slurry }}\left(1-\varphi_{n f}\right)
$$

For specific heat, Mulligan et al. [14] derived equation (2) from an energy balance. 


$$
\begin{gathered}
C_{p, e f f}=\frac{1}{\rho_{e f f}}\left(\rho_{n p} \varphi_{n f} \varphi_{n p} C_{p, n p} \rho_{M P C M} \varphi_{\text {Slurry }} \varphi_{M P C M} C_{p, M P C M}+\rho_{b f}(1-\right. \\
\left.\left.\varphi_{n f} \varphi_{n p}-\varphi_{\text {Slurry }} \varphi_{M P C M}\right) C_{p, b f}+\varepsilon \rho_{M P C M} \varphi_{\text {Slurry }} \varphi_{M P C M} \frac{\mathrm{H}}{\Delta T}\right)
\end{gathered}
$$

Thermal conductivity of mixtures containing nanoparticles and MPCMs is modeled using a "linear blending rule" for two components as given in equation (3). Other models have a deviation of less than $10 \%$ respect to this "linear blending rule" [15-17].

$$
k_{e f f} \cong x_{n f} k_{n f}+\left(1-x_{n f}\right) k_{\text {Slurry }}
$$

Thermal conductivity of MPCM slurry is calculated using Maxwell's relation [18] as given in equation (4).

$$
k_{\text {slurry }}=k_{b f} \frac{2 k_{b f}+k_{M P C M}+2 \varphi\left(k_{M P C M}-k_{b f}\right)}{2 k_{b f}+k_{M P C M}-\varphi\left(k_{M P C M}-k_{b f}\right)}
$$

Thermal conductivity of nanofluids particularly MWCNT-based nanofluid depends on various factors such as: nanoparticles volume concentration, temperature, aspect ratio, base fluid, amount of dispersants, sonication time and aggregation effects [28]. There are some discrepancies in conductivity behavior as a function of volume fraction of nanotubes. Nevertheless, all studies show a larger conductivity than predicted by Effective Medium Theory (EMT) in which is based Hamilton-Crosser (H-C) relation [19]. H-C relation does not consider other thermal conductivity improvement mechanisms such as liquid layering around nanoparticle surface, ballistic phonon transport, Brownian motion induced micro-convection and aggregation of nanoparticles [28, 29] which probably explain the deviation from $\mathrm{H}-\mathrm{C}$ equation. Some studies show a linear increase of $\mathrm{k}$ at small MWCNT volume fraction [30-34]. Given the complexity of considering all the above factors to model the thermal conductivity of nanofluid the following empirical model is employed, equation (5).

$$
\frac{k_{n f}}{k_{b f}}=1+c_{k} \varphi
$$

The nanofluid thermal conductivity coefficient $c_{k}$ is chosen to match the experimental data presented in literature [34].

Viscosity of MPCM slurries is modeled using a modified Einstein viscosity equation for large spherical particles in concentrated dispersions (diameter $>5$ um) equation (6) proposed by Toda and Furuse [20]. A correction factor $s$ that depends on particle diameter and concentration will curve fit experimental data in MPCM slurries.

$$
\mu_{\text {Slurry }}=\left[\frac{1-s 0.5 \varphi_{M P C M}-\varphi_{M P C M}}{\left(1-s \varphi_{M P C M}\right)^{2}\left(1-\varphi_{M P C M}\right)}\right] \mu_{b f}
$$


The viscosity of fibrous suspensions and MWCNT based nanofluid can be predicted by a modified Maron-Pierce equation (7) [21]. For high particle volume fraction.

$$
\mu_{n f}=\left(1-\frac{\varphi_{a}}{\varphi_{m}}\right)^{-2} \mu_{b f}
$$

where $\varphi_{m}$ defined as the maximum volume fraction at which the suspension viscosity becomes infinite, it depends on mean aspect ratio of MWCNT [22]. And $\varphi_{a}$ is an effective volume fraction of NP, which regard the presence of agglomerates, this variable depends on geometry, surfactants and NP volume fraction [23].

The effective kinematic viscosity of the mixture is calculated using the approach suggested by Taherian and Alvarado [13]. For each component the Viscosity Blending Index (VBI) is computed using equation (8). The Viscosity Blending Index (VBI) of the mixture is calculated using a simple mixing theory as seen in equation (9). Viscosity of the mixture is obtained using equation (8).

$$
\begin{gathered}
V B I=14.534 \ln [\ln (v+0.8)]+10.975 \\
V B I_{\text {Blend }}=x_{\text {Slurry }} V B I_{\text {Slurry }}+x_{n f} V B I_{n f}
\end{gathered}
$$

\subsection{Heat transfer problem}

The problem consists of a mixture flowing through a circular smooth pipe under turbulent regime with constant wall temperature $T_{w}=28^{\circ} \mathrm{C}$. With inlet temperature $T_{i n}=38^{\circ} \mathrm{C}$, Cooling loads $\dot{Q}_{L}=35 \mathrm{KW}, 106 \mathrm{KW}, 176 \mathrm{KW}$ and different temperature variations between the inlet and outlet were assumed $\Delta T=4,5$ and $6^{\circ} \mathrm{C}$. An inner pipe diameter $d=50.8 \mathrm{~mm}$ was selected. For each cooling load and temperature variation a flow rate of the base fluid can be computed from equation (10).

$$
\dot{Q}=\dot{m}_{b f} C p_{b f} \Delta T
$$

The effective flow rates of the blend are computed by equating heat capacity rates of working fluid and base fluids as expressed in equation (11). The system should also comply with equation (12) to satisfy the heat transfer phenomena.

$$
\begin{gathered}
C_{p, e f f} \dot{m}_{e f f}=C_{p, b f} \dot{m}_{b f} \\
\dot{Q}=\dot{m}_{e f f} C p_{e f f}\left(T_{w}-T_{i n}\right)\left(1-e^{-4 S t \lambda}\right)
\end{gathered}
$$

where St is the Stanton number and $\lambda$ is the dimensionless length defined in the nomenclature section. Friction losses are computed with equation (13) [24].

$$
P_{f}=\frac{16 m_{e f f^{3} L \bar{f}}}{2 \pi^{2} \rho d^{5}}
$$




\subsection{Entropy model}

An entropy generation rate expression (equation 14) for constant wall temperature under above mentioned condition was developed by Şahin [12].

$$
\dot{\mathrm{S}}_{\mathrm{gen}}=\dot{\mathrm{m}} \mathrm{C}_{\mathrm{p}}\left\{\ln \left[\frac{1-\tau \mathrm{e}^{-4 \mathrm{St} \lambda}}{1-\tau}\right]-\tau\left(1-\mathrm{e}^{-4 \mathrm{St} \lambda}\right)+\frac{1}{8} \overline{\mathrm{f}} \frac{\mathrm{Ec}}{\mathrm{St}} \ln \left[\frac{\mathrm{e}^{4 \mathrm{St} \lambda}-\tau}{1-\tau}\right]\right\}
$$

where dimensionless temperature difference $\tau$ and Eckert number $E c$ are defined by the expressions given in nomenclature.

Darcy friction factor for smooth surfaces is used equation (15) [25].

$$
\bar{f}=(0.790 \ln (R e)-1.64)^{-2}
$$

Nusselt number at $0.5 \leq \operatorname{Pr} \leq 2000$ equation (16) [25].

$$
N u=\frac{(\bar{f} / 8)(R e-1000) P r}{1+12.7\left(P^{2 / 3}-1\right)(\bar{f} / 8)^{1 / 2}}
$$

\section{Results}

Figure 1 and Figure 2 show results of entropy generation for turbulent flow regime with a cooling load of $35 \mathrm{KW}$ and $176 \mathrm{KW}$ respectively both with temperature variation of $5^{\circ} \mathrm{C}$. Results indicate that entropy generation is reduced with MPCM. In the cases studied, using MWCNT increases generation of entropy.

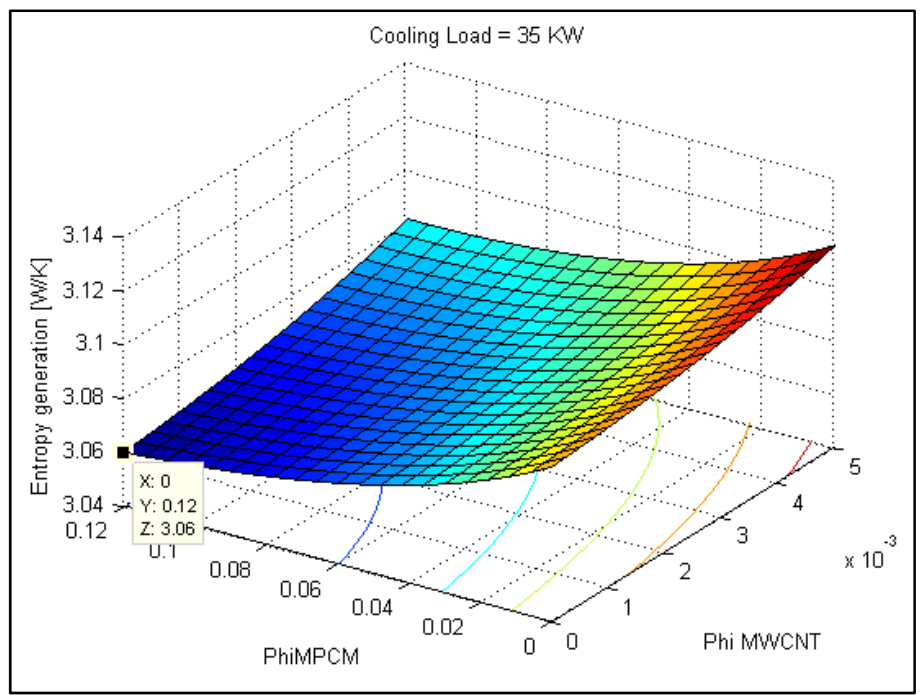

Figure 1: $\quad$ Entropy generated, cooling load $35 \mathrm{~kW}, 50.8 \mathrm{~mm}$ diameter pipe, $5^{\circ} \mathrm{C}$ fluid temperature variation between the inlet and outlet. 


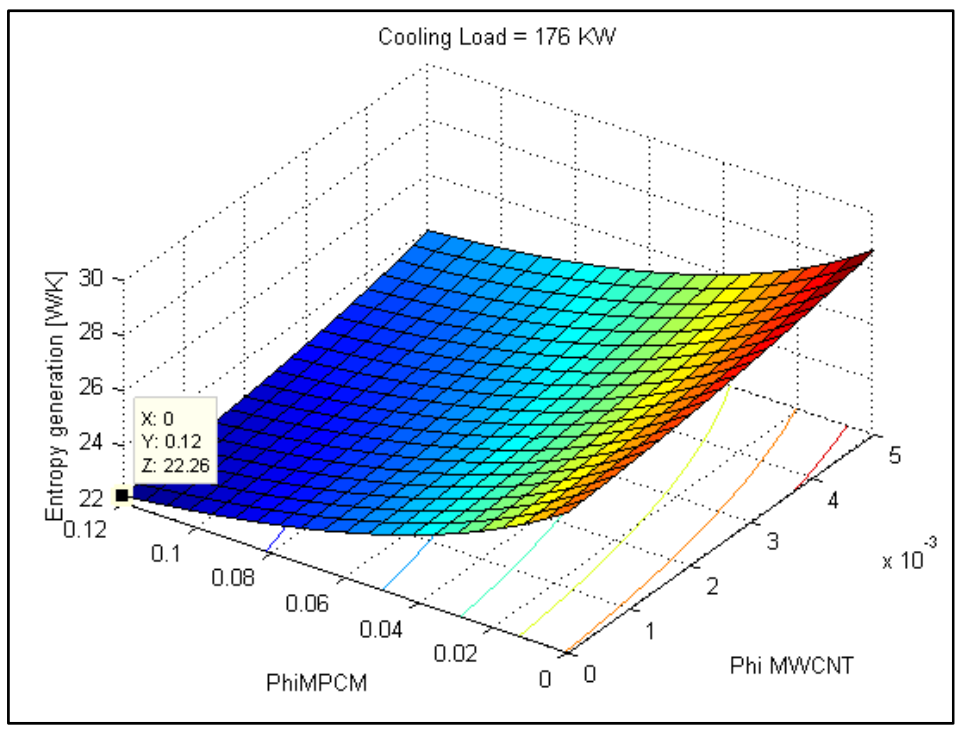

Figure 2: $\quad$ Entropy generated, cooling load $176 \mathrm{~kW}, 50.8 \mathrm{~mm}$ diameter pipe, $5^{\circ} \mathrm{C}$ fluid temperature variation between the inlet and outlet.

Pumping power for MPCMs slurries was computed. Figure 3 shows tendencies of friction losses at different cooling loads and temperature variations versus MPCM volume fraction. Figure 4 shows a comparison of friction losses at low and high heat loads.

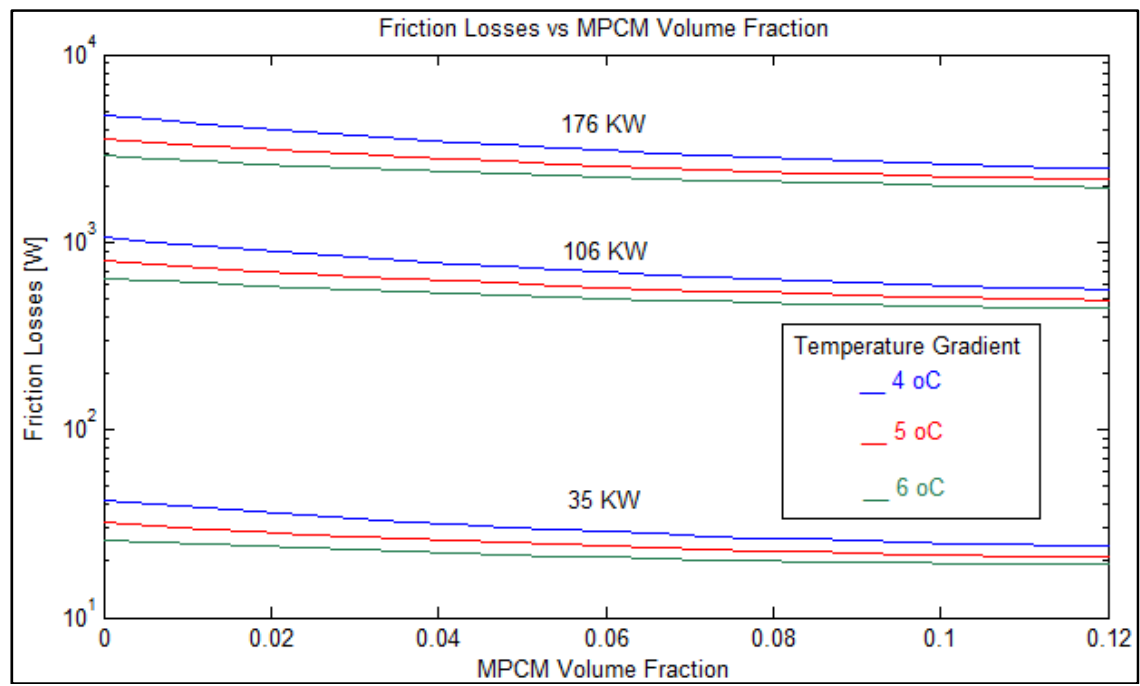

Figure 3: $\quad$ Friction loss for MPCMs slurries, $50.8 \mathrm{~mm}$ diameter pipe, several temperature variations and thermal loads. 


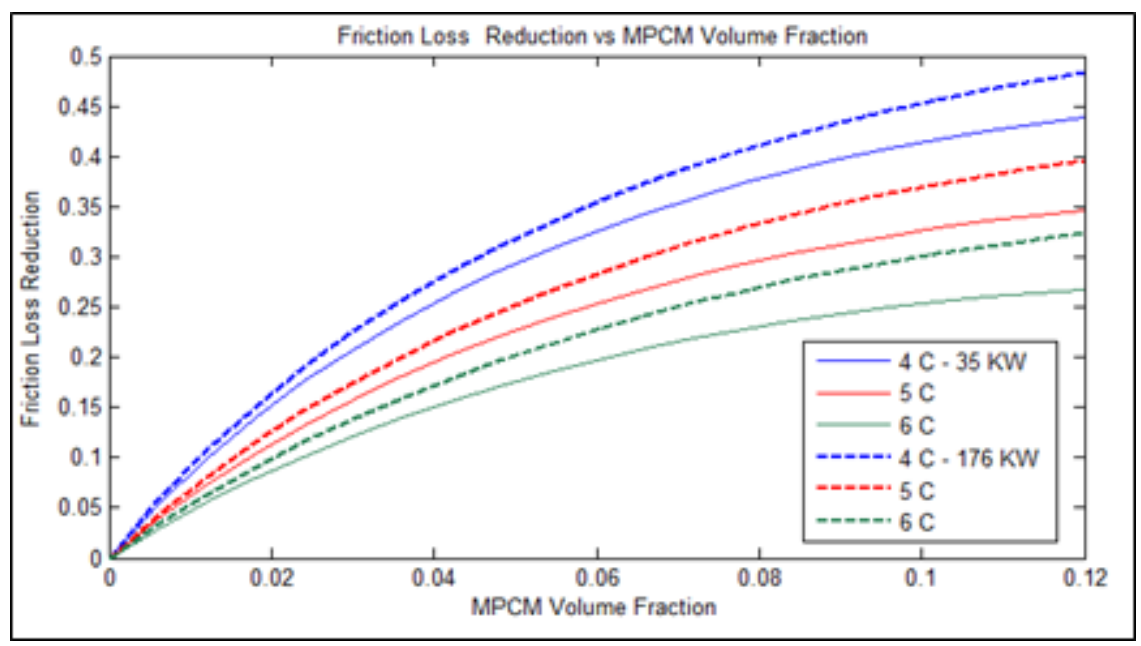

Figure 4: $\quad$ Friction loss percentage reduction for MPCMs slurries, $50.8 \mathrm{~mm}$ diameter pipe, several temperature variations and thermal loads.

\section{Discussion}

The models available in the literature for thermophysical properties of this ternary mixtures are insufficient. In the case of viscosity, there are few models to describe the behavior of a mixture of MPCM, MWCNT and water. It is found that MWCNT and MPCM morphology (length, diameter) affect final viscosity of the mixture even when concentrations are fixed $[20,26]$. The amount and type of surfactant used in preparing nanofluids also affects viscosity. In nanofluids case, ultrasonication time also affect viscosity in way that less time more agglomeration [26]. Models available fail to address Newtonian behavior of mixtures. While, MPCM slurries have Newtonian behavior even at high volume fraction [27], nanofluids exhibit a non-Newtonian behavior [7].

An analysis of equation (14) under the conditions of the present work shows that entropy generation due to heat transfer is kept constant (first and second terms). Increasing volume fraction of MPCM and nanoparticle in the mixture causes the dimensionless length to increase because advection in the fluid is reduced (lower Reynolds numbers and high viscosity). The Stanton number which represents the ratio between heat transfer due to convection and advection decreases in the same proportion. The amount St $\lambda$ remains constant despite having different concentrations of blend components. The increase of entropy shown in Figures 1 and 2 is due to friction entropy generation.

Using MWCNT based nanofluids is not recommended for the conditions analyzed, as can be observed in Figures 1 and 2. On the Other hand, MPCM decreases entropy generation as observed in Figures 1 and 2. The entropy generation observed is a result of changes in friction losses. 
For larger temperature gradients, the variation of viscosity will overcome benefits of the increment in thermal capacity in the blend by MPCMs as observed in Figure 3. A consequence of this is an increase on pipe length in order to dissipate the same thermal load. The reduction in fiction loss percentage is incremented by the addition of MPCMs at higher thermal loads and lower temperature gradients as seen in Figure 4.

\section{Conclusions}

An assessment of entropy generation of a heat transfer fluids working under constant wall temperature conditions in the turbulent regime is present. This methodology has the potential to be used as a tool to select an optimal composition of a fluid. However, further experimental research for thermophysical properties is needed to better understand the behavior of this type of fluids.

The thermal conductivity of the fluid is improved with nanofluids, but this improvement becomes negligible because advection which important in turbulent flow is reduced due to increase in viscosity which also increases friction losses. The overall effect is increasing entropy generation.

The increase of thermal capacity due to MPCMs results in a mass flow reduction for removing the same thermal load and as consequence friction losses is reduced. The effect of this increase overcomes the reduction in thermal conductivity and increases in viscosity due to the presence of MPCMs.

Friction losses are also affected by thermal load and temperature besides thermal capacity of the slurry. It is found that larger temperature gradients reduces friction losses. However, the relative friction loss reduction is mainly affected by heat capacity of the slurry which is improved by lower temperature gradients and larger thermal loads.

\section{Nomenclature}

$\begin{array}{ll}D & \text { Diameter } \\ f & \text { Friction factor } \\ C_{p} & \text { Specific heat } \\ H & \text { Latent heat } \\ T & \text { Temperature } \\ R e & \text { Reynolds number, }\left[4 \dot{m}_{\text {eff }} /\left(\pi \mu_{\text {eff }} d\right)\right] \\ P r & \text { Prandtl number, }\left[C_{p, e f f} \mu_{e f f} / K_{\text {eff }}\right] \\ N u & \text { Nusselt number, }\left[\bar{h} d / K_{\text {eff }}\right] \\ S t & \text { Stanton number, }\left[\bar{h} /\left(\rho_{\text {eff }} \bar{U} C_{p, e f f}\right)\right] \\ E c & \text { Eckert number, }\left[\bar{U}^{2} /\left(C_{p, e f f} T_{w}\right)\right] \\ \dot{Q} & \text { Cooling load } \\ \dot{S}_{g e n} & \text { Entropy generation rate }\end{array}$




$\begin{array}{ll}\dot{m} & \text { Mass flow rate } \\ L & \text { length } \\ P_{f} & \text { Friction loss } \\ \Delta T & \text { Temperature gradient } \\ k & \text { Thermal conductivity } \\ x & \text { Mass Fraction } \\ \mathrm{s} & \text { Correction factor }\end{array}$

\section{Greek Symbols}

$\begin{array}{ll}\rho & \text { Density } \\ \varphi & \text { Volumetric fraction } \\ \varepsilon & \text { Phase change fraction } \\ \mu & \text { Dynamic viscosity } \\ \tau & \text { Dimensionless temperature, }[(\operatorname{Tin}-T w) / T w] \\ \lambda & \text { Dimensionless length, }[L / d] \\ v & \text { Kinematic viscosity }\end{array}$

\section{Subscripts}

$\begin{array}{ll}\text { np } & \text { Nanoparticles } \\ \text { eff } & \text { Effective } \\ \text { MPCM } & \text { Microencapsulated phase change material } \\ \mathrm{Nf} & \text { Nanofluid } \\ \mathrm{Bf} & \text { Base fluid } \\ \text { in } & \text { Inlet } \\ \mathrm{w} & \text { Wall } \\ \mathrm{a} & \text { Effective } \\ \mathrm{m} & \text { Maximum }\end{array}$

\section{References}

[1] Choi, S. U., Zhang, Z. G., and Keblinski, P., Nanofluids. Encyclopedia of Nanoscience and Nanotechnology, 6(1) pp. 757-773, 2004.

[2] Alvarado, J. L., Marsh, C., Sohn, C., Thermal Performance of Microencapsulated Phase Change Material Slurry in Turbulent Flow Under Constant Heat Flux. International Journal of Heat and Mass Transfer, 50(9-10) pp. 1938-1952, 2007.

[3] Buongiorno, J., Venerus, D. C., Prabhat, N.A., Benchmark Study on the Thermal Conductivity of Nanofluids. Journal of Applied Physics, 106(9) pp. 094312-094312-14, 2009.

[4] Saidur, R., Leong, K. Y., and Mohammad, H. A., A Review on Applications and Challenges of Nanofluids. Renewable and Sustainable Energy Reviews, 15(3) pp. 1646-1668, 2011. 
[5] Das, S.K., Choi, S.U., Yu, W., Nanofluids: science and technology. Wiley-Interscience Hoboken, NJ, 2008.

[6] Zhao, C., and Zhang, G. H., Review on Microencapsulated Phase Change Materials (MEPCMs): Fabrication, Characterization and Applications. Renewable and Sustainable Energy Reviews, 15(8) pp. 3813-3832, 2011.

[7] Alvarado, J. L., Marsh, C., Thies, C., Soriano, G., \& Garg, P., Characterization of thermal properties and heat transfer behavior of microencapsulated phase change material slurry and multiwall carbon nanotubes in aqueous suspension. In ASME 2007 International Mechanical Engineering Congress and Exposition (pp. 1771-1777). American Society of Mechanical Engineers, 2007.

[8] Tumuluri, K., Alvarado, J. L., Taherian, H., Thermal Performance of a Novel Heat Transfer Fluid Containing Multiwalled Carbon Nanotubes and Microencapsulated Phase Change Materials. International Journal of Heat and Mass Transfer, 54(25) pp. 5554-5567, 2011.

[9] Singh, P. K., Anoop, K., Sundararajan, T., Entropy Generation due to Flow and Heat Transfer in Nanofluids. International Journal of Heat and Mass Transfer, 53(21) pp. 4757-4767, 2010.

[10] Bejan, A., A Study of Entropy Generation in Fundamental Convective Heat Transfer. Journal of Heat Transfer, 101. pp. 718, 1979.

[11] Bejan, A., Entropy generation minimization: the method of thermodynamic optimization of finite-size systems and finite-time processes. CRC, 1995.

[12] Şahin, A. Z., Entropy Generation in Turbulent Liquid Flow through a Smooth Duct Subjected to Constant Wall Temperature. International Journal of Heat and Mass Transfer, 43(8) pp. 1469-1478, 2000.

[13] Taherian, H. and Alvarado, J. L., System Analysis of MPCM Slurry Enhanced with Carbon Nanotubes as Heat Transfer Fluid. ASHRAE Transactions, ASHRAE, 116, pp. AB-10, 2010.

[14] Mulligan, J., Colvin, D., and Bryant, Y., Microencapsulated Phase-Change Material Suspensions for Heat Transfer in Spacecraft Thermal Systems. Journal of Spacecraft and Rockets, 33(2) pp. 278-284, 1996.

[15] Assael, M., Dymond, J., Papadaki, M., Correlation and Prediction of Dense Fluid Transport Coefficients. III. N-Alkane Mixtures. International Journal of Thermophysics, 13(4) pp. 659-669, 1992.

[16] Assael, M., Chen, C., Metaxa, I., Thermal Conductivity of Suspensions of Carbon Nanotubes in Water. International Journal of Thermophysics, 25(4) pp. 971-985, 2004.

[17] Focke, W. W., Correlating Thermal-Conductivity Data for Ternary Liquid Mixtures. International Journal of Thermophysics, 29(4) pp. 1342-1360, 2008.

[18] Maxwell, J.C., A treatise on electricity and magnetism. Clarendon Press, 1881.

[19] Hamilton, R., and Crosser, O., Thermal Conductivity of Heterogeneous Two-Component Systems. Industrial \& Engineering Chemistry Fundamentals, 1(3) pp. 187-191, 1962. 
[20] Toda, K. and Furuse, H., Extension of Einstein's Viscosity Equation to that for Concentrated Dispersions of Solutes and Particles. Journal of Bioscience and Bioengineering, 102(6) pp. 524-528, 2006.

[21] Halelfadl, S., Estellé, P., Aladag, B., Viscosity of Carbon Nanotubes Water-Based Nanofluids: Influence of Concentration and Temperature. International Journal of Thermal Sciences, 71. pp. 111-117, 2013.

[22] Mueller, S., Llewellin, E., and Mader, H., The Rheology of Suspensions of Solid Particles. Proceedings of the Royal Society A: Mathematical, Physical and Engineering Science, 466(2116) pp. 1201-1228, 2010.

[23] Wolthers, W., Duits, M., Van Den Ende, D., Shear History Dependence of the Viscosity of Aggregated Colloidal Dispersions. Journal of Rheology (1978-Present), 40(5) pp. 799-811, 1996.

[24] White, F. M. "Fluid Mechanics, WCB", 1999.

[25] Incropera, F.P., Lavine, A.S., and DeWitt, D.P. Fundamentals of heat and mass transfer. John Wiley \& Sons, 2011.

[26] Garg, P., Alvarado, J. L., Marsh, C., Carlson, T. A., Kessler, D. A., \& Annamalai, K., An experimental study on the effect of ultrasonication on viscosity and heat transfer performance of multi-wall carbon nanotubebased aqueous nanofluids. International Journal of Heat and Mass Transfer, 52(21), 5090-5101, 2009.

[27] Zhang, G. H., and Zhao, C., Thermal and Rheological Properties of Microencapsulated Phase Change Materials. Renewable Energy, 36(11) pp. 2959-2966, 2011.

[28] John Philip, P.D., Thermal properties of nanofluids. Advances in Colloid and Interface Science 183-184, pp. 30-45, 2012.

[29] Keblinski P, Eastman JA, Cahill DG., Nanofluids for thermal transport. Mater Today; 8 pp. 36-44, 2005.

[30] Lifei Chen, H. X., Yang Li, W. Y., Nanofluids containing carbon nanotubes treated by mechanochemical reaction. Thermochimica Acta 477 pp. 21-24, 2008.

[31] J. Glory, M. B., Helezen, M., Mayne-L'Hermite, M. and Reynaud, C., Thermal and electrical conductivities of water-based nanofluids prepared with long multiwalled carbon nanotubes. Journal of Applied Physics. 103, 094309, 2008.

[32] Hwang, Y.J., Ahn, Y.C., Shin, H.C., Lee, C.G., Kim, G.T., Park, H.S., Lee, J.K., Investigation on characteristics of thermal conductivity enhancement of nanofluids. Current Applied Physics 6, pp. 1068-1071, 2006.

[33] Indhuja, A., Suganthi, K.S., Manikandan, S., Rajan, K.S., Viscosity and thermal conductivity of dispersions of gum arabic capped MWCNT in water: Influence of MWCNT concentration and temperature. Journal of the Taiwan Institute of Chemical Engineers 44, pp. 474-479, 2013.

[34] Halelfadl, S., Maré, T., Estellé, P., Efficiency of carbon nanotubes water based nanofluids as coolants. Experimental Thermal and Fluid Science 53, pp. 104-110, 2014. 